\title{
Article \\ Dynamics in Complex Systems Amidst Crisis 2008+: Financial Regulatory and Supervisory Reflections
}

\author{
Piotr Łasak * (D) and Sławomir Wyciślak (D)
}

check for updates

Citation: Łasak, Piotr, and Sławomir Wyciślak. 2022. Dynamics in Complex Systems Amidst Crisis 2008+: Financial Regulatory and Supervisory Reflections. Risks 10: 33. https://doi.org/10.3390/risks10020033

Academic Editors: Mogens Steffensen and Krzysztof Jajuga

Received: 30 September 2021

Accepted: 31 January 2022

Published: 2 February 2022

Publisher's Note: MDPI stays neutral with regard to jurisdictional claims in published maps and institutional affiliations.

Copyright: (C) 2022 by the authors. Licensee MDPI, Basel, Switzerland. This article is an open access article distributed under the terms and conditions of the Creative Commons Attribution (CC BY) license (https:// creativecommons.org/licenses/by/ $4.0 /)$.
Faculty of Management and Social Communication, Jagiellonian University, Łojasiewicza Street 4, 30-348 Krakow, Poland; slawomir.wycislak@uj.edu.pl

* Correspondence: piotr.lasak@uj.edu.pl

\begin{abstract}
Every financial crisis triggers some regulatory and supervisory changes related to the ensuing threats. These regulations usually address specific types of risks and reduce them but do not protect the entire system from another crisis. The aim of this study was to develop a conceptual framework of financial system resilience based on the theoretical approach of complex system theory and its explanation of these systems' self-adaptation. Our analysis embraces the time since the 2008+ financial crisis in the United States. We argue that the digitalization of financial markets may contribute to the greater safety of the banking sector. We adopted blockchain technology for the pattern of self-modification mechanisms of the financial system. The main findings highlight that the blockchain technology incorporated into the system approach and applied to financial regulation and supervision can significantly improve the safety of the financial markets.
\end{abstract}

Keywords: bank crisis; blockchain technology; complex system theory; financial markets regulation; financial markets supervision

\section{Introduction}

The aim of this study was to develop a conceptual framework of financial system resilience based on the theoretical approach of complex system theory. We elaborated this framework by adopting different aspects of the theory (resilience, suboptimal behaviors, adaptation of the system) and narrative literature review. We focused especially on the body of work related to the complexity and the case of the Lehman Brothers bankruptcy and the post-crisis efforts to rebuild global, regional, and national financial market regulatory and supervisory architecture and adjust this architecture to the new economic situation. To achieve the aim of the study, we provided answers to the following analytical and explanatory research questions:

- What are the main parts of the complex system theory and the systems' reaction in the context of the financial crisis (namely: subsystems, relationships amongst subsystems, reinforcing and balancing loops, delayed and unintended effects of relationships within complex systems in crisis)?

- What were the main regulatory and supervisory actions on a global, regional, and national level that aimed to improve the financial system's safety after the global financial crisis?

- How is the financial system enhancing its resilience, and how might the complex system theory explain the mechanisms?

- How can the resilience of the financial system be improved by the application of distributed ledger technology (blockchain) to the existing financial architecture and the mechanisms of its self-modification after a major crunch?

We elaborated a theoretical, conceptual approach based on a narrative literature review to answer the research questions. The layout of the paper consists of seven sections. The introduction constitutes Section 1. In Section 2, we present the conceptual background of 
the complex system theory and the identified research gap related to the abovementioned research questions. In Section 3, we describe the methodology for the literature review. Section 4 presents the case of the bankruptcy of the bank Lehman Brothers and then Section 5 the consequences of the bankruptcy for the whole financial system, based on the complex system theory. Section 6 presents the self-modification of the financial system. The discussion, our main contribution to the considered theory, and the final conclusions and recommendations for further research are presented in Section 7.

\section{Conceptual Background of the System Approach}

The system approach can be perceived as a meta-theory developed to address complex problems. It focuses on identifying systems, feedback, control, and equilibrium in a fundamental sense. Systems theory is the foundation for understanding multidisciplinary systems (Adams et al. 2013) and solving complex problems. The system approach is about the shift from the parts to the whole as complex systems are wholes whose emerging properties cannot be reduced to smaller parts. System approach also means a shift from objects to relations as objects are seen as networks of relationships embedded in more extensive networks. The system approach is also about changing from structures to processes, as all structures are seen as manifestations of underlying processes. The system approach is also about change from measuring to mapping. Methodologies need to move toward mapping and identifying patterns because relationships and processes cannot be measured in the traditional sense due to their emerging properties (Vargo et al. 2017).

Scientists seek and scrutinize patterns and tendencies in complex systems with the help of a system approach. Achievements earned within the system approach may be perceived as the next steps in the explanation of the phenomenon of complexity. Therefore, three stages of development of system theories may be identified. The first wave, right after WWII, is connected to the development of computers and the application of feedback employing machines. The second phase is associated with the development of cybernetics and system dynamics, and finally, the third stage is based on new understanding of equilibrium in discontinuation theories (Turner and Baker 2019).

General systems theory, cybernetics, chaos theory, as well as catastrophe theory aim at explaining deterministic systems' behavior. There is a different adaptive complex system explanation model, and research in this area suggests that emerging order stems from interactions at lower aggregation levels (Turner and Baker 2019). Adaptive complex systems can both affect their environment and change their structure without external input.

Complexity theory is composed of chaos theory, dissipative structure theory, and complex adaptive systems theory. Whereas the chaos theory and the dissipative structure theory focus on general model development, adaptive complex system theory applies a multi-agent approach (Schwaninger 2009).

Apart from becoming a new and increasingly popular perspective, the systems approach to the world is also a powerful inspiration for theorizing in social sciences. Since the times of Aristotle, it has been known that the whole is more than the sum of its parts. The relations between the parts are complex and non-trivial. The actions undertaken in one subsystem may have consequences for another subsystem that cannot be foreseen or controlled. The whole also influences the parts, and different kinds of elements, also unstable, can create a stable whole. Such a broad view is often serving as a general frame of reference. Although this reductionistic framework has served science well in the past, such as during the Industrial Revolution, it is inadequate to serve science well today due to the complexities of the modern world (e.g., global warming, information overload, globalization, and geopolitical unrest).

Complexity theory views systems as being non-linear; thus, future states are unpredictable. As a system transitions from simple to complex, the predictive mechanisms become less reliable (Turner and Baker 2019). A starting point for thinking about systems science is the view that every concrete thing is a system or part of one and that natural systems can be arranged into a "complexity hierarchy", in which the "levels" represent 
increasingly complex systems that embed systems from the "lower" levels, and every level corresponds to some kind of system (Rousseau 2018). The underlying shift from closed to open systems thinking is the acceptance of the importance of interacting with the environment, as the survival of individual organizations depends on the ability to adapt to markets. Systems thinking consists of analysis and synthesis. The analysis focuses on structure. It reveals how things work. Synthesis focuses on a function that reveals why things operate as they do. Synthesis and analysis are complementary. The analysis looks into the system; synthesis looks outward to consider the system's environment (Ackoff 1999).

Our study implemented a classical procedure of system identification to develop an analytical model based on the distinguished variables. The latter mirrors the reflection, research, design, and intervention stages of understanding (Arnold and Wade 2015). The whole process of applying the complex system approach to a particular economic problem consists of several steps:

- Identifying the problem-providing a portal into complex system understanding and being essential in the eventual development of solutions that might bring about positive change for complex system problems;

- Defining the fundamental goals of the system and the way it functions-system resilience;

- Determining system borders-understanding what makes a difference between the system and its environment;

- Identification of the system environment-understanding system stakeholders;

- Feedback between system and environments-interacting with the environment, as the survival of individual organizations depends on the ability to adapt to markets, technologies, and other situations and organization can impact the environment;

- Describing system features;

- Defining subsystems of the system-within these subsystems, some tasks can be considered to be multidisciplinary activities that cross traditional functional department boundaries;

- Recognizing interconnections-identifying critical connections between parts of a system (subsystems);

- Identifying and reinforcing and balancing loops, non-linear relationships, and dynamic behavior. There are two types of feedback; one is known as negative feedback with balancing loops and the other as positive feedback with amplifying loops;

- The emergence of new behaviors - this phase embraces interconnections, the way they combine into feedback loops, and the way these feedback loops influence subsystems create dynamic behavior within a system;

- Adaptation, when a system is in a new equilibrium - the shape of the system after the changes and mechanisms provide accomplishment of the system's functions, new bonds in the system, and new relations providing greater endurance for the system.

We focused on the situation following the global financial crisis. As a consequence of the collapse of a systemically important bank ("too big to fail", the case of Lehman Brothers), contagion mechanisms create risk for the whole financial system. In response, a new regulatory and supervisory reaction is implemented to provide greater resilience of the system. Despite these initiatives, there are still some flaws, and a new approach is needed.

\section{Methodology and Literature Review}

The authors conducted a narrative literature review to describe and critically evaluate a body of work regarding complexity, system approach, complex system theory, the case of the Lehman Brothers bankruptcy, and the following regulatory and supervisory changes in the financial system. Open-access databases were chosen for this study. Selected databases encompassed scholar.google.com, iEEEXplore, Arxiv, ScienceDirect, Scopus, and Web of Science. Google Scholar is a powerful open-access database that archives journal articles and "gray literature", including conference proceedings, thesis, and reports. Norris et al. (2008) 
compared Google and Google Scholar to other open-access search engines. They found that Google and Google Scholar performed the best. Combined, these two sources could discover more than three-quarters of open access publications identified in their study. We followed these suggestions and based our analysis on these sources.

Research questions were the drivers for the selection of keywords. We started our literature search using the keywords "system theory financial crisis", "complex system theory financial crisis", "complexity financial crisis", "system thinking financial crisis", and "resilience of the financial system". We separated words and used them with "AND", for example, "system theory" and "financial crisis"; "complex system theory" and "financial crisis"; "complexity" and "financial crisis"; and "system dynamics" and "financial crisis". Afterward, we added "Lehman Brothers" and "banks" to combinations of used words in a search process. "Chaos theory", "agent-based modeling", and "complex network" complemented used keywords.

After the initial screening of the titles, 120 studies were identified. As the narrative reviews focus on gathering relevant information that provides both context and substance to the authors' overall argument (Xiao and Watson 2019), we excluded studies that provide little insight into the researched topics. Overall, 57 studies from the initial search were included for further analysis. The difference between the number of studies in the bibliography, which accounts for 59 , is because of including papers on methodological matters.

Based on the narrative literature review that takes into account the global financial crisis, the consequences of the collapse of the investment bank Lehmann Brothers (Benos et al. 2012; Christopoulos et al. 2011; De Haas and Van Horen 2012; Fernando et al. 2012; Swedberg 2010; Wiggins and Metrick 2015), the regulatory and supervisory reforms of the financial system afterward (Avgouleas 2009; Davis 2009; Laeven et al. 2010), and the reaction of the financial systems of smaller and greater size, described in the literature embedded in the complex system theory (Bezemer 2012; Brancaccio et al. 2018; Liu and Arunkumar 2019; Zhu et al. 2018), we made synthesis and identified the current situation. We realized that the literature linked the complex system approach and the safety of the financial system usually has a technical nature, and there is a significant research gap lacking detailed explanation of the mechanisms leading to the greater resilience of the financial system. We did not intend to write a report about the application of the complex system theory. Still, using deductive reasoning, we propose a concept based on the complex system approach aimed at improving the resilience of the financial system to external shocks. In our inference process appeared a reflection, leading to a modification of the existing way of thinking (first-order), suggesting a modification of the current financial regulatory and supervisory approach that could lead to the improvement of the financial system's resilience (second-order). In consequence, we aim to provide some recommendations, leading to the assurance of greater stability of the financial system in the future.

\section{The Causes of Lehmann Brothers Bankruptcy}

The bankruptcy of the investment bank Lehman Brothers had far-reaching consequences. This was the collapse of a 158-year-old bank, the largest bankruptcy in the history of the United States, and the beginning of the global financial crisis. When the New York Stock Exchange collapsed, many entities affiliated with Lehman Brothers were affected, and eventually, the crisis moved to many other countries (Johnson and Mamun 2012).

There are many reasons for the collapse of Lehman Brothers. These reasons were undoubtedly very important from the perspective of the banking sector because the bank has fully demonstrated the nature of investment banks operating in the U.S. market. The most important causes include (Zingales 2008):

- Financial market mechanisms (low interest rates and lack of market transparency);

- Underestimation of risks in the financial market flawed regulation;

- Banks' investment policies;

- Weaknesses of corporate governance. 
The first cause of the Lehmann Brothers' problems was the mechanisms of financial market functioning. As highlighted in the literature, the main cause of the turmoil was the combination of a credit boom and a housing bubble (Acharya and Richardson 2009; Roubini and Mihm 2011). The low interest rates were crucial for the creation of a speculative bubble in the real estate market. Investors in the market believed that prices would always go up. Moreover, the market was very opaque, mainly due to the securitization process, which became common among the U.S. banks. The direct trigger was the sharp increase in the federal funds' interest rate during 2004-2006, which was a cause of the subsequent decline in housing prices (McDonald and Stokes 2013).

The second cause of the bank's failure was underestimating the risk of the financial markets and opaque regulations. Three decades of deregulation and reliance on self-regulation by financial institutions were essential for the pre-crisis situation of risk cumulation (Financial Crisi Inquiry Commission 2011). The regulations and supervisors failed to address the dangers which occurred in the financial market. Moreover, the massive application of asset securitization and participation of investment and commercial banks in the process contributed to the risk underestimation (Helleiner 2011).

The third cause of Lehman Brothers' collapse was its investment policy. Significant were the high leverage and the reliance on short-term debt financing. The asset-to-equity ratio before the collapse was higher than 30. Additionally, the short-term debt-financed more than $50 \%$ of the assets (Zingales 2008). It increased the threat of "bank run" in the situation of lack of investors' confidence. As a consequence of the situation, the bank could not meet its short-term obligations. This led to the loss of market confidence and withdrawal of services and credit lines by other banks from Lehman Brothers. Together with the interbank market, the same situation occurred in the retail market, where the confidence of lenders and customers also weaned. In a search for liquidity, Lehman reduced its gross asset base by $\$ 147$ billion (Mawutor 2014). An important cause of the Lehman Brothers problems was the Repo 105 transactions. The bank could not meet its current obligations, so it decided to employ the aggressive but deceitful accounting off-balance-sheet device to remove securities and troubled liabilities from its balance sheet while reporting its quarterly financial results. These operations were recorded as sales instead of loans. The reduction in assets and liabilities created the impression that the Lehman financial statements were much better. When the reporting period finished, the bank repurchased the securities and its financial statements went back to the previous inferior position (Azadinamin 2013; Hines et al. 2011; Jeffers 2011).

The fourth cause of the Lehman Brothers collapse was pointed weaknesses of the corporate governance system (Pirson and Turnbull 2015) argue that the failure in communication hierarchy should be treated as one of the crucial reasons for the bank's collapse. The bank's staff could not detect high-risk loans and undertake appropriate action. Managers were not able to understand risks, and they were using the wrong tools for risk assessment. Considering the bank's structure, there were many other problems, such as insufficient level of internal control, insufficient decomposition of decision making, and many other problems related to the corporate governance issues. Another dimension of the corporate governance problem is the compensation system. The excessive number of executive payments led to corporate governance problems, and finally, it impacted the situation of the bank (Mazzola 2018).

\section{The Consequences for the Financial System}

\subsection{The Reaction of the System and the Escalation Effect}

The important issue related to the Lehman Brothers collapse is the financial system's broader consequences. Some analytics even argue that bankruptcy has worsened the creditworthiness of all financial institutions. The situation is even called the "Lehman Brothers effect", which is related to the following crash on the stock market and panic among many financial institutions. The threats also moved to the real economy (Sieczka et al. 2011). 
Regarding the impact of the Lehman Brothers collapse, the consequences might be direct and indirect. When considering the direct consequences, attention should be paid to the industrial firms that received equity and debt underwriting, advisory, analyst, and market-making services from the bank. The recent studies reveal that the Lehman Brothers collapse caused significant negative abnormal returns after the bankruptcy. The companies that used Lehman Brothers as a lead underwriter during the 10 years leading to September 2008 lost on average around 5\% of their market value over a 7-day period after the Lehman Brothers bankruptcy. The losses were significantly larger than for firms that were equity underwriting clients of other large investment banks (Fernando et al. 2012).

The second direct consequence was triggered by the credit contagion channels through which Lehman Brother's bankruptcy affected other firms. Here are two significant risks, "counterparty risk" and "information transmission". It is substantial that the most potent negative effect concerned the financial industry. Chakrabarty and Zhang (2012) highlight that the size of institutions and the complexity of their business networks in the financial services industry may lead to strong contagion effects through counterparty risk or information transmission channels. Capital market mechanisms play a significant role, confirmed by the facts: Immediately after the Lehman Brothers collapse, the stocks of other banks declined by $2.9 \%$, and the stocks of primary dealers declined by $6 \%$ (Johnson and Mamun 2012).

The literature highlights that financial crises are not isolated events, and the global financial system is inherently unstable, so it is essential to apply appropriate economic policies (Sau 2013). The regulatory issues were described in the literature related to complex system theory in numerous papers. There are proposals of a more efficient institutional structure that is able to prevent crisis and manage crises when they occur as well as suggestions of the general improvement in the international banking sector supervision, treated as a whole system. Viorica (2021) highlights that institutional structure is an essential element of international financial architecture, and she highlights the need to strengthen this structure. Other conceptions focus on macroprudential regulations, but they are divided into two different approaches. The first group of proposals focuses on the improvements of the current system, whereas the other suggests implementing new approaches to banking system regulation and supervision. Evans and Li (2019) highlight the need for significant changes in the current international regulatory and supervisory architecture based on the Basel Committee of Banking Supervision. Farmer et al. (2012) suggest orienting the management of the financial markets around the approach that links these markets with real economy and macroeconomic modelling and better understanding the processes in the real economy which lead to financial crises. Karaev et al. (2017) also refer to banking sector regulation and supervision. They argue that effective system of macroprudential regulation aimed at achieving financial stability should take into account existing modular-hierarchical architecture of banking system. In their opinion contagion in the banking system is similar to contagion defined by medical sciences (epidemic), and the supervisory and regulatory bodies should use the network analysis of financial system and focus their activity on modularity and heterogeneity of the system. The same point is of view is presented by Levin and Lo (2015), who opt for the application of financial regulatory architecture, the approach applied in biology as the best option to address the financial system instability. In their opinion a biological approach based on the complex system approach is able to address the current financial regulatory challenges (too big to fail, adaptive regulation, homeostatic mechanisms, and robustness and resiliency) (Levin and Lo 2015).

\subsection{The Response of the System}

In addition to the direct consequences, the Lehman Brothers collapse has solid indirect implications. The collapse caused a significant shock to the world's financial markets. The contagion transmission had different mechanisms, especially: (a) the correlated information channel; (b) the liquidity channel; and (c) the risk premium channel (Wiggins and Metrick 2015). It is highlighted that the first two mechanisms are related to 
investor behavior, whereas the last is related to the possibility of counterparty contagion (when investors withdraw from some markets and hoard funds). As highlighted, all of the effects, namely direct and indirect, are leading to the financial system contagion (Glasserman and Young 2016).

From the complex system theory, the contagion mechanisms create risk for the whole financial system. The theory provides the mechanisms leading to the improvement of the financial system's security (Figure 1). According to the presented diagram, the control parameters play a crucial role, and they are defined by the country's regulatory and supervisory architecture.

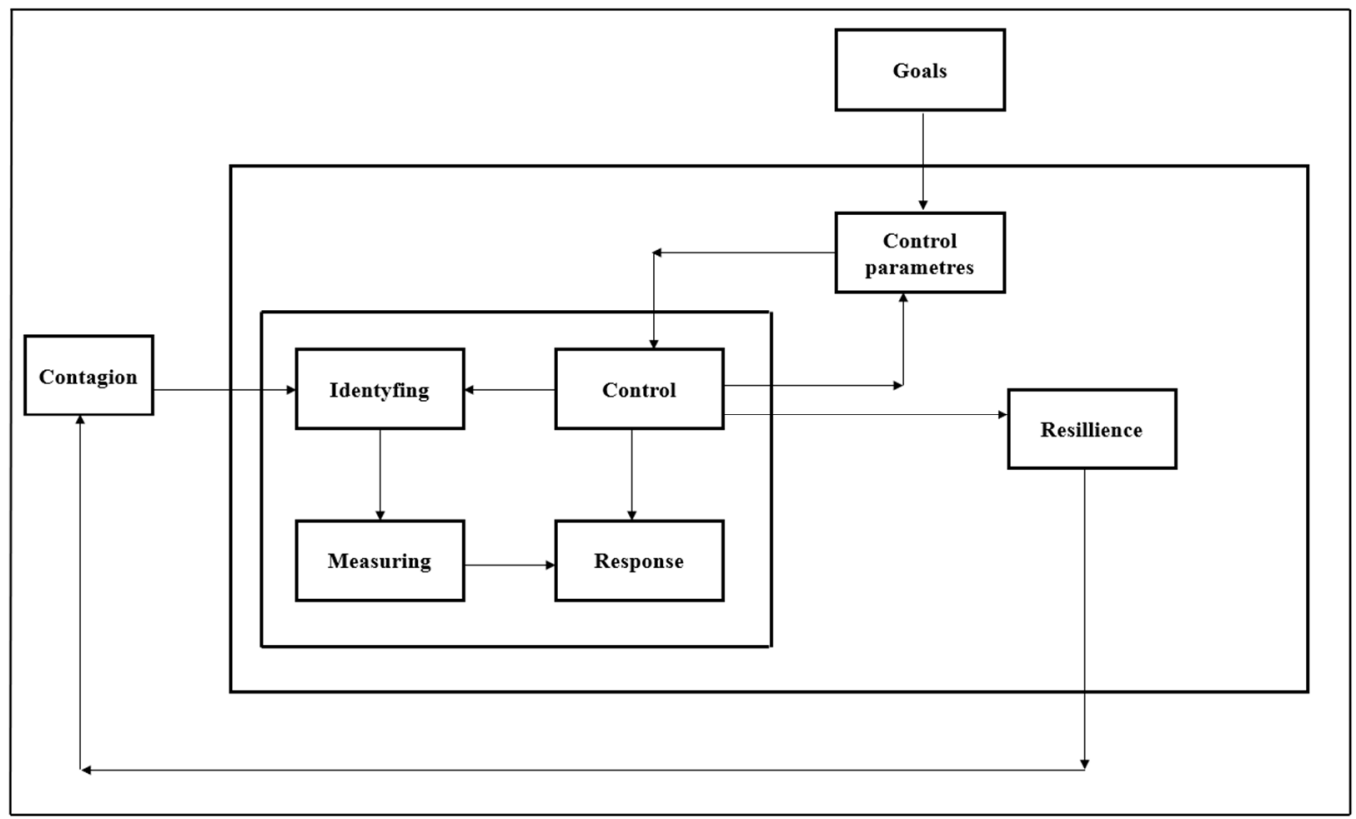

Figure 1. The interpretation of mechanisms leading to the financial system's security.

The structure of banking supervision is different in different countries, but the functions are similar. Usually, the supervisory body is responsible for a control function, identifying the risks and measuring the safety level. Microprudential regulations execute all these activities. Such macroprudential regulations are treated as control parameters. They are responsible for identifying, measuring, responding, and controlling the risk involved. Among such regulations might be enumerated: capital requirements, liquidity requirements, and risk exposure regulations (Polizatto 1992). Despite their concern of single entities, it is significant that they are also crucial for the entire financial system (de Haan et al. 2019). They are responsible for identifying, measuring, responding, and controlling the system's risk. It is essential that the international regulatory authorities are aware of the weaknesses of the existing regulatory solutions and coordinate the process of unification and convergence. They want to unify global banking standards and provide a level playing field in different countries, reduce the regulatory asymmetry, and improve the efficiency of such regulatory bodies (Coelho et al. 2020).

The regulatory authorities are also responsible for the resilience of the system. If the system encounters threats and the existing regulatory solutions cannot prevent these threats, the regulatory and supervisory system is modified. After the global financial crisis, many changes have been made in this area. These changes were of a two-way nature. On the one hand, modifications to the existing prudential regulations were introduced (Basel Committee on Banking Supervision 2017), and on the other hand, new regulations concerning systemic risk appeared. In the latter area, the resolution mechanism can be mentioned in particular (Cohen 2010; Pellerin and Walter 2012).

The changes introduced for the former prudential regulations implemented by the Basel Capital Accords can be interpreted as the evolution of the system. The system 
evaluates and learns, and the occurring tensions (resulting in a decline of the prudential regulations in banks below the acceptable minimum limits) lead to redefining the microprudential indicators. The new forms of these regulations should provide that banks do not go beyond the scope that ensures the system's stability.

Better adjustment of the regulatory system to the existing conditions and greater security of a given financial market positively impact other (foreign) markets. This mechanism is shown in Figure 2.
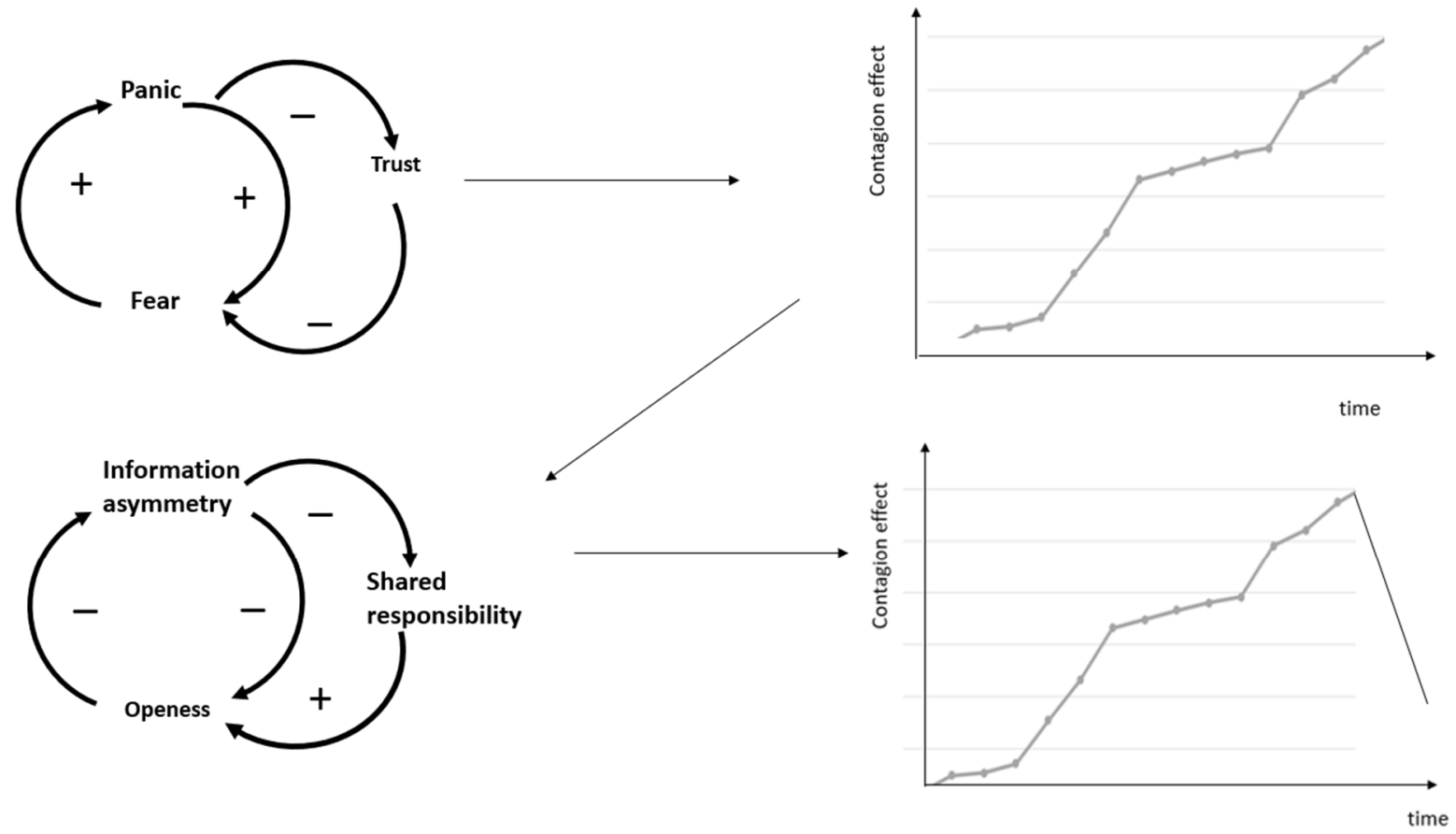

Figure 2. Escalation and de-escalation causal loops.

In the beginning, the higher fear (lack of money market, as a consequence of such events as the Lehman Brothers collapse) leads to higher panic and lower trust. Consequently, there is a more significant threat in the money market and a higher contagion effect - the spillover effect embracing other money markets (phase 1). The theory of complex systems implies the reaction of the system. Here is a great role for the control parameters (identification, measuring, response, and control). In our case, the reaction is embodied in the response from the regulatory and supervisory system. The microprudential norms and limits inform of the higher level of risk. The whole system reacts with better adjusted microprudential regulations and additional initiatives. After the last financial crisis, it has resulted in identifying the systemic risk and implementing some macroprudential measures.

Moreover, the whole architecture of financial supervision was improved (both on national and international levels). Apart from the microprudential regulation improvements, important macroprudential activities are leading to lower information asymmetry and higher openness of the system. They are caused by the stress testing, banks' capital adequacy review (lower information asymmetry), and creation of the international financial supervisory architecture (under the roof of the Financial Stability Board). The increasing regulations and supervision are leading to higher shared responsibility and finally to lower contagion effect (phase 2).

\section{Modifications of the System}

The theory of complex systems provides a full explanation of how the system evolves. In the beginning, it should be assumed that there are two possible research orders. The first is indicated in Figure 3. In this order, the previous system failures lead to regulatory 
adjustments. Some changes are implemented in the banking sector regulations and supervision which should finally lead to the system's equilibrium. The improvements (regulatory changes) can be made on the national or international level. Regarding the case of Lehman Brothers, it is significant that the scope of the crisis was international, as the consequence of the scope of the activity of investment banks (indicated as T.B.T.F.). In response, the new regulations and adjustments in supervisory architecture have an international dimension. After the global financial crisis, the leading supervisory role was taken by the Financial Stability Board, which became the global coordinator of all the further activities. The international body monitors and makes recommendations regarding the global financial system (About the FSB 2018).

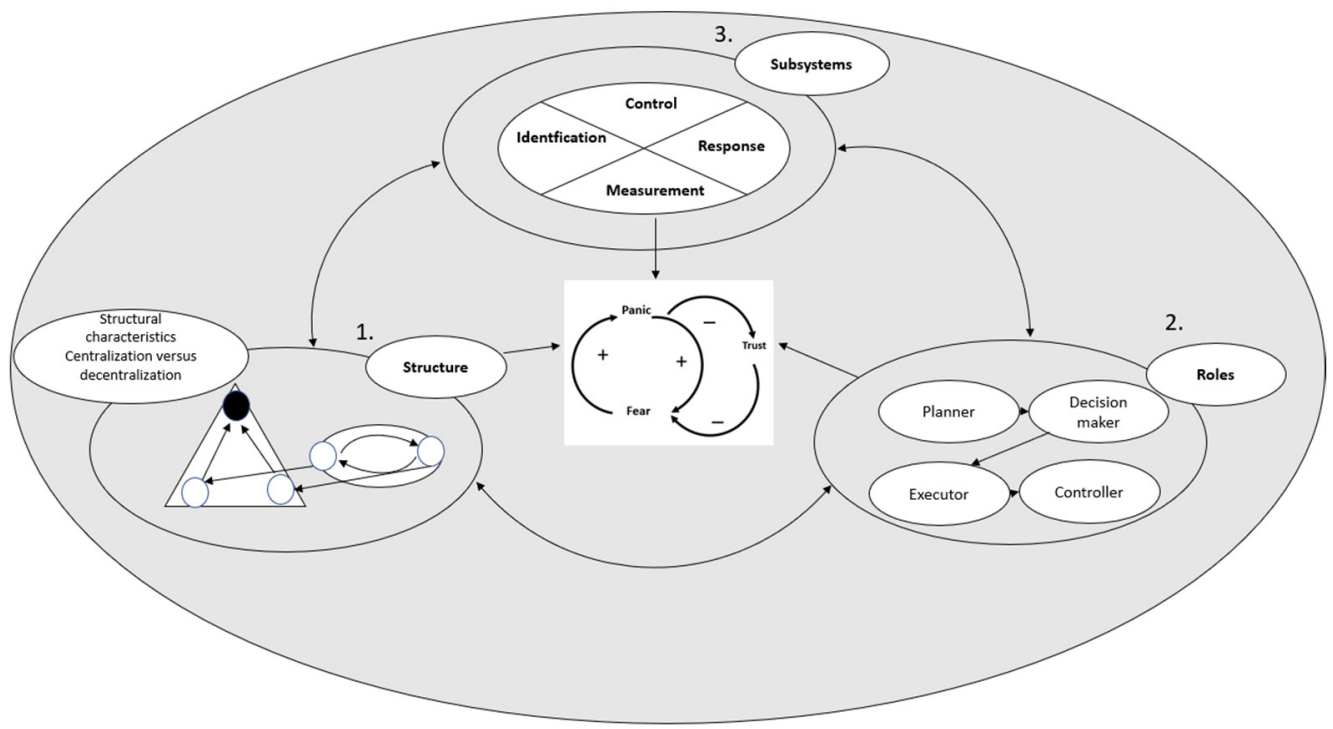

Figure 3. The mechanisms of the system self-modification after a major crunch.

Specialized institutions technically implement the solutions elaborated on the international level by the FSB. The crucial role is played by the Basel Committee for Banking Supervision (BCBS). The international regulatory and supervisory order is centralized, but the local supervisory architecture is decentralized. The best example here is the European Union, where the crucial competencies belong to national authorities.

The banking supervisors play the roles. This means that they set the microprudential and macroprudential regulations, are responsible for their compliance, monitor the situation of the local financial market, and modify the regulations when necessary. Despite the fact that such national differences, such as the structure of the financial system, model of supervisor (integrated, sectoral, or twin peaks), and their location, make some differences, the basic role is always the same (Goodhart et al. 2013; Llewellyn 2006). The same approach is taken in the case of macroprudential regulation and supervision. Here is also an important division into international dimension (played by the FSB, BCBS, and IMF) and national (where apart from supervisory agencies, a significant role is played by central banks). The main goal on the macroprudential level is to provide safety and soundness for the financial system as a whole (Lastra 2015).

The consequence of the regulatory and supervisory architecture is the financial system's stability. The most important implication of the complexity theory is that the system is going to modify itself (phase 3). Here is the greatest role of the control parameters, which are providing the resilience of the system.

The second research order is defined by the possibility of adaptation of the theory of complex systems to the national financial markets regulatory and supervisory bodies (safety net). The interpretation of such mechanisms is presented in Figure 1. According to the mechanisms, the national financial regulatory and supervisory authorities set 
the financial system security (resilience). The domestic regulatory bodies set the safety thresholds (control parameters) consistent with the microprudential regulations. They are responsible for ongoing control of the financial system security, identification of potential risks, the response from the regulatory system, and identification of existing threats. This approach presupposes that the safety net automatically adapts to the changes of the situation, providing suitable resilience of the whole system.

\section{Discussion and Conclusions}

The presented mechanism explains the self-modification of financial systems after such bankruptcies as the Lehman Brothers collapse. The response from the system provides its resilience. There are, however, some incapacities and areas that elude the system. The first and foremost issue is that all regulatory reforms have cyclical results. Every financial problem is ushering in new regulations and sometimes far-reaching reforms. Still, later, they are systematically weakening over time as markets recover, and finally, loosening of the rules takes place (Levin and Lo 2015).

The areas which elude the regulatory and supervisory modifications may include local banks (cooperative banks) which cannot be treated as too big to fail, but as a whole subsector of the banking sector, they also cause a systemic risk. Theoretically, the regulatory and supervisory bodies are oriented toward such subsectors, but in fact, their supervision of these areas is more difficult and less efficient. Another threat is posed by the shadow banking system. There are many institutions and mechanisms created before and after the global financial crisis that is not covered by the system of banking supervision. Shadow banking developed to such a size that was compared to the size of traditional banking (Pozsar et al. 2010). Moreover, it is not only important in developed banking sectors, such as the U.S. and EU, but also in many emerging markets (Buchholz 2020; Ghosh et al. 2012; Sun 2019). Currently, the digitalization of financial markets also provides new challenges, which require further, constant modification of the financial system.

The enumerated threats and many others create a need for a better adjusted regulatory and supervisory approach. One of the requirements of such an approach is to ensure observability of the system, which in consequence enables its controllability. In order to achieve such a state, we propose such modification in the supervisory and regulatory approach that will provide observability. It is a conception based on the application of blockchain technology. In such modification, the former structure of the system is kept, and new parts are included between the supervisory roles and subsystems (Figure 4). The crucial change between the former regulatory approach and the modified one is that blockchain technology provides the possibility to reduce suboptimal behaviors.

Blockchain technology makes the ability to access information and information sharing easier and facilitates real-time analysis. It enables two or more systems' agents to work simultaneously on the same kind of information, hence resulting in a better prospect for the transformational (the utilization of information) characteristics of a system. Blockchain architecture can reduce information asymmetry while at the same time protecting sensitive data. Transparency makes the suboptimization behaviors of subsystems difficult. Hence, the total system finds its optima in terms of resilience.

When the whole system optimum prevails, not all subsystems are optimum. As a result, it is hard to expect that the sum of subsystems' optima will necessarily lead to the total system's optimum. In other words, if the subsystems suboptimize but work toward the whole system's optimum, they will, in aggregate, reach a better total system optimum than if each tries to optimize its own system separately. The principle of suboptimization means that when the individual subsystems optimize their actions, the whole system does not work optimally. There is no contradiction in promoting, on the one hand, solutions worked out on a centralized basis and, on the other, implementation carried out by the decentralized decision units (Van Gigch 1991). 


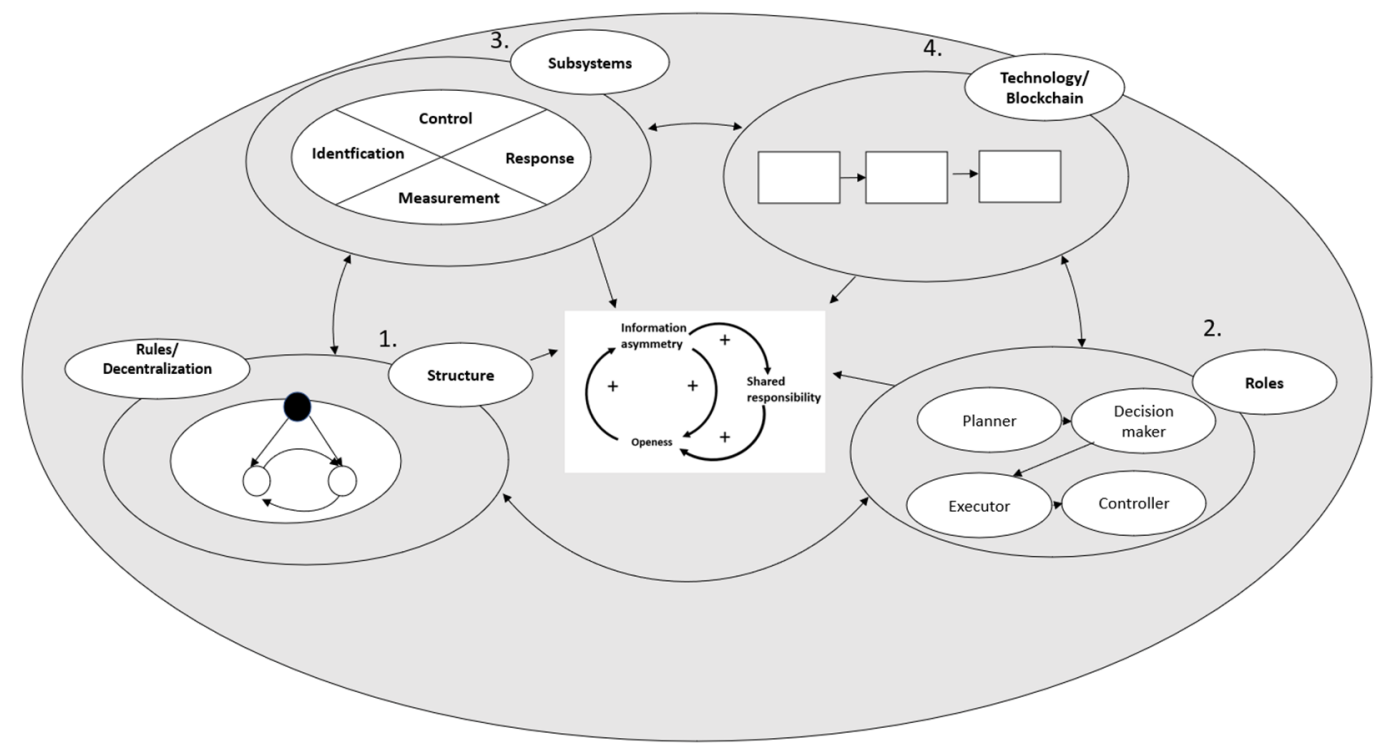

Figure 4. The concept of the new architecture of the finance system to increase resilience.

The impact of the blockchain application on the whole financial system is presented in Figure 5. When every participant has the same information, it creates consensus among all of them. In consequence, the information asymmetry decreases, and it reduces the possibility of suboptimal behavior. In consequence, it increases the resilience of the system and reduces the risk of a future crisis.

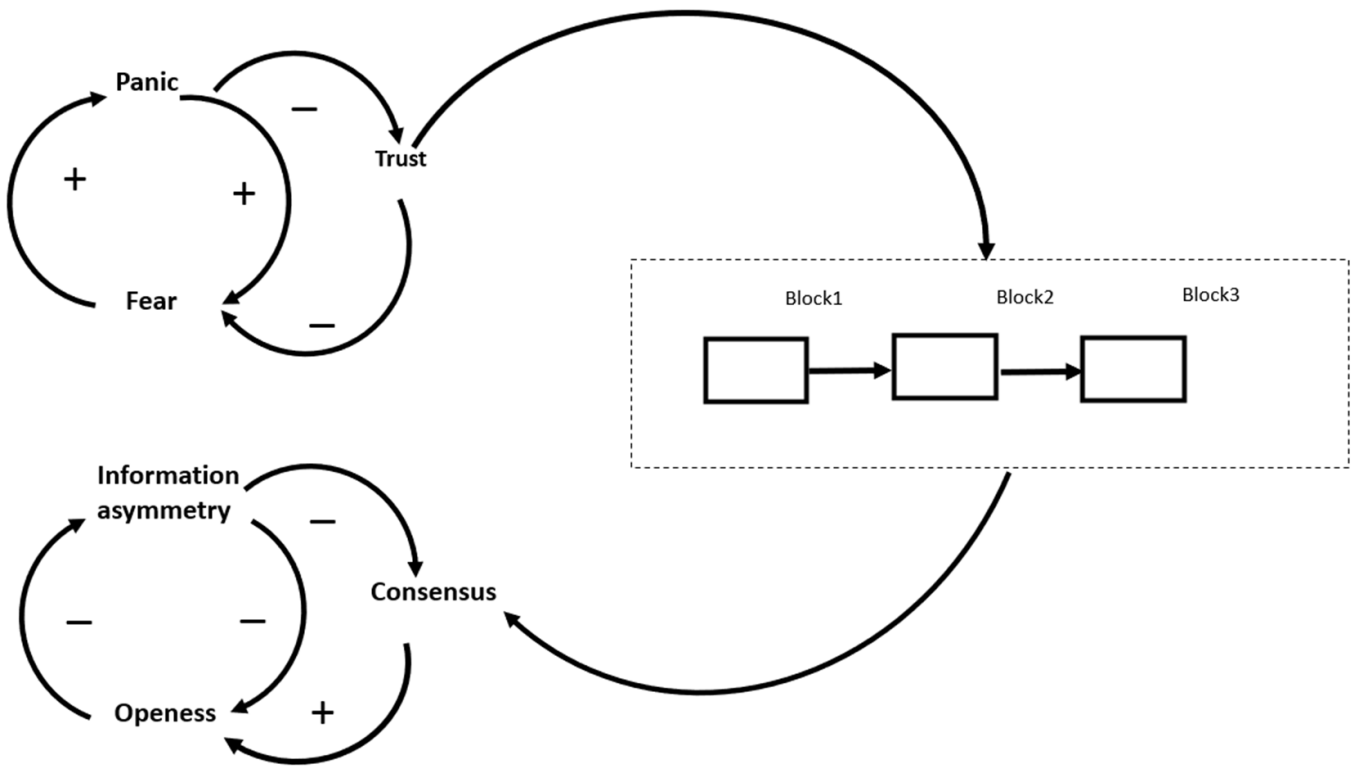

Figure 5. The mechanism of suboptimal behavior reduction as a consequence of blockchain application.

The blockchain solution provides the opportunity of removing inadequacies often associated with current financial systems, such as opportunism, fraud, money laundering, and corruption, as any transaction will be immutable, verifiable, and traceable. The more the financial system applies distributed ledger technology, the more it moves to a delegative style, and the more decisions are delegated or even automated, while trust (within and among financial subsystems) becomes replaced by mathematics. Immutable computer code-one or more smart contracts linked together and deployed on a blockchain-encourages actors within subsystems to self-organize. The code defines governance, i.e., the rules that are implemented within smart contracts. This shifts balance within a financial system from a hierarchical structure to a distributed structure. Blockchain removes the need for 
trusted intermediaries and enables irrefutable transactions and decisions to be executed automatically and autonomously across time and space. As a result, it compensates for tensions between control and autonomy, competition and collaboration, governance costs, and resilience amongst subsystems.

We would like to highlight that questions have been asked of how to improve the financial regulatory and supervisory architecture for many years. Our contribution is a reflection that proposes a new approach to increase the safety of the financial system. We hope that this contribution and the presented findings are significant for the process of shaping the financial market's regulatory and supervisory systems. The proposed theoretical framework contributes to the theory by explaining the mechanisms leading to greater resilience of the financial system-it addresses the identified research gap. Further, we concluded that the self-adaptation of the financial system, described by the complex system theory, is not a sufficient mechanism. We argue that for greater resilience of the financial system, it is necessary to implement blockchain technology into regulatory and supervisory activities.

The framework of our analysis is based on theory, and consequently, we describe the reaction of the financial regulatory and supervisory institutions to such cases as the Lehman Brothers bankruptcy. We highlighted that after such collapses, some changes are implemented in the banking sector regulations and supervision which should finally lead to the equilibrium of the system (the rationale is presented in Figure 3 and further in the text). This is the typical reaction to a crisis in the banking sector. We highlighted that the microprudential and macroprudential regulations are modified in such circumstances, and these modifications are oriented toward providing higher safety of the whole system in the future. However, in some regulatory systems, such modifications are insufficient, and they represent only a short-term reaction. In response to the need for a better adjusted regulatory and supervisory approach, we formulated a suggestion that should be developed based on the application of blockchain technology in the regulatory and supervisory system. Based on the system approach, we created a model that uses blockchain and enriches the current discussion on the security of the financial system. The technology contributes to the system optimization and can reach a better adjusted total system optimum. The new framework, based on blockchain inclusion, contributes to the theory and has important policy implications. We hope that the presented analysis may serve as a reference point for the introduction of further reforms in the field of financial market regulation and supervision. Our approach improves the transparency of the operations, reducing the tensions between subsystems and improving the resilience of the system as a whole.

We are aware of many challenges facing the effective implementation of the proposed solution. In an operational sense, the details will matter, namely the system's connectivity (ability to integrate), the unification of common regulatory and supervisory approaches, willingness for information sharing (the problem of data sensitivity), and unification of data exchange standards. All of these problems together with the question about the impact of blockchain on system centralization and resilience create the potential avenue for further research. The significant future research questions may include:

- How can the improvement of the current financial regulatory and supervisory systems be operationalized by implementing blockchain technology?

- What enablers can encourage governments to implement blockchain-based regulatory and supervisory solutions?

- What are the obstacles to implementing blockchain technology into existing financial supervision systems?

- Is it possible to unify the national regulatory and supervisory systems using blockchain solutions?

These questions can provide inspiration for future research related to the financial system's resilience. Our theoretical considerations should be translated into operational models enabling their implementation in practice. 


\begin{abstract}
Author Contributions: Conceptualization, P.Ł. and S.W.; methodology, P.Ł. and S.W.; formal analysis, P.Ł. and S.W.; investigation, P.Ł. and S.W.; resources, P.Ł. and S.W.; writing-original draft preparation, P.Ł. and S.W.; writing-review and editing, P.Ł. and S.W. All authors have read and agreed to the published version of the manuscript.
\end{abstract}

Funding: This research is funded by the Institute of Economics, Finance and Management and the Department of Management and Social Communication, Jagiellonian University in Kraków.

Conflicts of Interest: The authors declare no conflict of interest.

\title{
References
}

About the FSB. 2018. WWW Document. Available online: https:/ /www.fsb.org/about/ (accessed on 27 July 2021).

Acharya, Viral V., and Matthew Richardson. 2009. Causes of the Financial Crisis. Critical review 21: 195-210. [CrossRef]

Ackoff, Russel L. 1999. Ackoff's Best: His Classic Writings on Management, 1st ed. New York: Wiley.

Adams, Kevin M., Peggy T. Hester, and Josepg M. Bradley. 2013. A historical perspective of systems theory. Presented at the Industrial and Systems Engineering Research Conference, San Juan, PR, USA, May 18-22. Available online: https:/ /www.researchgate.net/ publication/288782223_A_historical_perspective_of_systems_theory (accessed on 28 June 2021).

Arnold, Ross D., and Jon P. Wade. 2015. A definition of systems thinking: A systems approach. Procedia Computer Science 44: 669-78. [CrossRef]

Avgouleas, Emilios. 2009. The global financial crisis and the disclosure paradigm in European financial regulation: The case for reform. European Company and Financial Law Reform 6: 1-41. [CrossRef]

Azadinamin, Amirsaleh. 2013. The Bankruptcy of Lehman Brothers: Causes of Failure E Recommendations Going Forward. Zug: Swiss Management Center University. [CrossRef]

Basel Committee on Banking Supervision. 2017. Basel III: Finalising Post-Crisis Reforms. Basel: Bank for International Settlements, Available online: https://www.bis.org/bcbs/publ/d424.pdf (accessed on 20 September 2021).

Benos, Evangelos, Rodney Garratt, and Peter Zimmerman. 2012. Bank Behaviour and Risks in CHAPS Following the Collapse of Lehman Brothers. Bank of England Working Paper 451. Available online: https://papers.ssrn.com/sol3/papers.cfm?abstract_ $\mathrm{id}=2092668$ (accessed on 23 September 2021).

Bezemer, Dirk J. 2012. The economy as a complex system: The balance sheet dimension. Advances in Complex Systems 15: 1-22. [CrossRef]

Brancaccio, Emiliano, Raffaele Giammetti, Milena Lopreite, and Michelangelo Puliga. 2018. Centralization of capital and financial crisis: A global network analysis of corporate control. Structural Change and Economic Dynamics 45: 94-104. [CrossRef]

Buchholz, Katharina. 2020. Infographic: Where Shadow Banking Is Growing. Available online: https://www.statista.com/chart/2353 4/nbfi-growth-by-country (accessed on 9 August 2021).

Chakrabarty, Bidisha, and Gaiyan Zhang. 2012. Credit Contagion Channels: Market Microstructure Evidence from Lehman Brothers' Bankruptcy. Financial Management 41: 320-43. Available online: https://doi.org/10.1111/j.1755-053X.2012.01194.x (accessed on 14 September 2021).

Christopoulos, Apostolos G., John Mylonakis, and Pavlos Diktapanidis. 2011. Could Lehman Brothers' collapse be anticipated? An examination using CAMELS rating system. International Business Research 4: 11-19. [CrossRef]

Coelho, Roodrigo, Fernando Restoy, and Raihan Zamil. 2020. Convergence in the prudential regulation of banks-What is missing? Bank for International Settlements, FSI Insights on Policy Implementation 24: 1-21.

Cohen, Hollace T. 2010. Orderly Liquidation Authority: A New Insolvency Regime to Address Systemic Risks. University of Richmond Law Review 45: 1143-229.

Davis, Kevin. 2009. Financial regulation after the global financial crisis. Australian Economic Review 42: 453-56. [CrossRef]

de Haan, Jakob, Zhenghao Jin, and Zhou Chen. 2019. Micro-Prudential Regulation and Banks' Systemic Risk. The Nederlandsche Bank Working Paper. Amsterdam: The Nederlandsche Bank, pp. 656-35.

De Haas, Ralph, and Neeltje Van Horen. 2012. International shock transmission after the Lehman Brothers collapse: Evidence from syndicated lending. American Economic Review 102: 231-37. [CrossRef]

Evans, John, and Yifei Li. 2019. A review of global banking regulation under an assumption of complexity. Annales of Actuarial Science 13: 320-33. [CrossRef]

Farmer, J. Doyne, Mauro Gallegati, Cars Hommes, Alan Kirman, Paul Ormerod, Silvano Cincotti, Angel Sanchez, and Dirk Helbing. 2012. A complex systems approach to constructing better models for managing financial markets and the economy. The European Physical Journal Special Topics 214: 295-324. [CrossRef]

Fernando, Chitru S., A. D. May, and W. L. Megginson. 2012. The Value of Investment Banking Relationships: Evidence from the Collapse of Lehman Brothers. The Journal of Finance 67: 235-70. [CrossRef]

Financial Crisi Inquiry Commission. 2011. The Financial Crisis Inquiry Report: Final Report of the National Commission on the Causes of the Financial and Economic Crisis in the United States. New York: US Government Publishing Office.

Ghosh, Swati, Ines. G. del Mazo, and İnci Ötker-Robe. 2012. Chasing the Shadows: How Significant Is Shadow Banking in Emerging Markets? Economic Premise 88: 1-7.

Glasserman, Paul, and H. Peyton Young. 2016. Contagion in Financial Networks. Journal of Economic Literature 54: 779-831. [CrossRef] 
Goodhart, Charles, Philipp Hartmann, David T. Llewellyn, Liliana Rojas-Suarez, and Steven Weisbrod. 2013. Financial Regulation: Why, How and Where Now? London: Routledge.

Helleiner, Eric. 2011. Understanding the 2007-2008 Global Financial Crisis: Lessons for Scholars of International Political Economy. Annual Review of Political Science 14: 67-87. [CrossRef]

Hines, Charles, J. Kreuze, and S. Langsam. 2011. An analysis of Lehman Brothers bankruptcy and Repo 105 transactions. American Journal of Business 26: 40-49. [CrossRef]

Jeffers, Agatha. 2011. How Lehman Brothers Used Repo 105 to Manipulate Their Financial Statements. Journal of Leadership, Accountability and Ethics 8: 44-55.

Johnson, Mark Antony, and Abdullah Mamun. 2012. The failure of Lehman Brothers and its impact on other financial institutions. Applied Financial Economics 22: 375-85. [CrossRef]

Karaev, Alan, M. Melnichuk, T. Guev, and G. Mentel. 2017. Stability analysis of the banking system: A complex systems approach. Journal of International Studies 10: 273-84. [CrossRef]

Laeven, Luc, Deniz Igan, Stijn Claessens, and Giovanni Dell'Ariccia. 2010. Lessons and Policy Implications from the Global Financial Crisis. International Monetary Fund Working Paper 44. Washington, DC: International Monetary Fund.

Lastra, Rosa M. 2015. Systemic risk and macroprudential supervision. In The Oxford Handbook of Financial Regulation. Edited by Molonet Niamh, Eilis Ferran and Jennifer Payne. Oxford: Oxford University Press, pp. 309-10.

Levin, Simon A., and Andrew W. Lo. 2015. Opinion: A new approach to financial regulation. Proceedings of the National Academy of Science of the United States of America 112: 12543-44. [CrossRef] [PubMed]

Liu, Chang, and Nior Arunkumar. 2019. Risk prediction and evaluation of transnational transmission of financial crisis based on complex network. Cluster Computing 22: 4307-13. [CrossRef]

Llewellyn, David T. 2006. Institutional structure of financial regulation and supervision: The basic issues. In World Bank Seminar Aligning Supervisory Structures with Country Needs. Washington, DC: World Bank.

Mawutor, John Kwaku Mensah. 2014. The Failure of Lehman Brothers: Causes, Preventive Measures and Recommendations. Research Journal of Finance and Accounting 5: 85-91.

Mazzola, Paul. 2018. Power and Influence in the U.S. Investment Banking Industry-A Case Study of Lehman Brothers. Wollongong: University of Wollongong Thesis Collection.

McDonald, John F., and Houston H. Stokes. 2013. Monetary Policy and the Housing Bubble. The Journal of Real Estate Finance Economics 46: 437-51. [CrossRef]

Norris, Michael, Charles Oppenheim, and Fytton Rowland. 2008. The citation advantage of open-access articles. Journal of the American Society for Information Science and Technology 59: 1963-72. [CrossRef]

Pellerin, Sabrina, and John R. Walter. 2012. Orderly Liquidation Authority as an Alternative to Bankruptcy. Economic Quarterly 98: 1-31.

Pirson, Michael, and Shann Turnbull. 2015. The future of corporate governance: Network governance-A lesson from the financial crisis. Human Systems Management 34: 81-89. [CrossRef]

Polizatto, Vincent. 1992. Prudential regulation and banking supervision. In Financial Regulation: Changing the Rules of the Game. Washington, DC: World Bank, pp. 283-319.

Pozsar, Zoltan, Tobias Adrian, Adam Ashcraft, and Hayley Boesky. 2010. Shadow banking. Federal Reserve Bank of New York Staff Report 458: 1-74. [CrossRef]

Roubini, Nouriel, and Stephen Mihm. 2011. Crisis Economics: A Crash Course in the Future of Finance. London: Penguin Books.

Rousseau, David. 2018. On the architecture of systemology and the typology of its principles. Systems 6: 7. [CrossRef]

Sau, Lino. 2013. Instability and Crisis in Financial Complex Systems. Review of Political Economy 25: 496-511. [CrossRef]

Schwaninger, Markus. 2009. System Dynamics in the Evolution of the Systems Approach. Encyclopedia of Complexity and Systems Science 9: 8974-87.

Sieczka, Pawel, Didier Sornette, and Janusz A. Holyst. 2011. The Lehman Brothers Effect and Bankruptcy Cascades. European Physical Journal B 3: 257-69. [CrossRef]

Sun, Guofeng. 2019. China's Shadow Banking: Bank's Shadow and Traditional Shadow Banking. BIS Working Paper 822. Beijing: China's Shadow Banking: Bank's Shadow and Traditional Shadow Banking (bis.org), pp. 1-47.

Swedberg, Richard. 2010. The structure of confidence and the collapse of Lehman Brothers. In Markets on Trial: The Economic Sociology of the U.S. Financial Crisis: Part A. Bingley: Emerald Group Publishing Limited, vol. 30, pp. 71-114.

Turner, John, and Rose Baker. 2019. Complexity Theory: An Overview with Potential Applications for the Social Sciences. Systems 1: 4. [CrossRef]

Van Gigch, John P. 1991. System Design Modeling and Metamodeling. Berlin: Springer.

Vargo, Stephen L., Kaisa Koskela-Huotari, Steve Baron, Bo Edvardsson, Javier Reynoso, and Maria Colurcio. 2017. A systems perspective on markets-Toward a research agenda. Journal of Business Research 79: 260-68. [CrossRef]

Viorica, Lopotenco. 2021. Development of the New International Financial Architecture at the National Financial Systems Level. Warsaw: RS Global.

Wiggins, Rosalind, and Andrew Metrick. 2015. The Lehman Brothers Bankruptcy H: The Global Contagion. Yale Program on Financial Stability Case Study. New Haven: Yale Program.

Xiao, Yu, and Maria Watson. 2019. Guidance on conducting a systematic literature review. Journal of Planning Education and Research 39: 93-112. [CrossRef] 
Zhu, Yangguang, Feng Yang, and Wuyi Ye. 2018. Financial contagion behavior analysis based on complex network approach. Annals of Operations Research 268: 93-111. [CrossRef]

Zingales, Luigi. 2008. Causes and effects of the Lehman Brothers bankruptcy. In Commitee on Oversight and Government Reform U.S. House of Representatives. Chicago: University of Chicago, pp. 23-25. 